\title{
Dos documentos coserianos de la época de su llegada a Montevideo
}

Los dos documentos de la mano de Eugenio Coseriu que publicamos a continuación, Repartido no. 68 y Preliminares para una discusión, fueron presentados por Adolfo Elizaincín en agosto de 2008 en el XV congreso de la Asociación de Linguiística y Filología de América Latina (ALFAL) celebrado en Montevideo, durante el cual se celebró un coloquio bajo el título Eugenio Coseriu, memória e atualidade, organizado por Inês Erthal y Paulo Soethe, de la Universidade Federal do Paraná (Brasil).

Los originales, propiedad del archivo privado de Adolfo Elizaincín y ahora generosamente cedidos al Archivo Coseriu de Tubinga, se pueden visualizar haciendo clic en los enlaces debajo de los títulos respectivos. Fueron ligeramente corregidos y ortográficamente actualizados en la transcripción.

La razón de la publicación de estos documentos en Energeia reside no tanto en los temas concretos tratados, ya no actuales en lo concreto (aunque algunos de sorprendente actualidad en lo general), sino más bien en su valor como documentos históricos y en el hecho de que representen una muestra de la enorme fuerza e iniciativa con la que Eugenio Coseriu llega a Uruguay en el año 1950, rompiendo con las tradiciones y revolucionando por completo la situación en la Facultad de Humanidades. Y los más sorprendente es que desde la vista hacia el pasado podemos afirmar que gran parte del ambicioso plan presentado en Repartido no. 68 se cumplió en los años 1950 y convirtió a Montevideo con su escuela de lingüística en uno de los principales centros lingüísticos del mundo. 


\section{Eugenio Coseriu}

\section{Repartido No. 68 [1950]}

\section{Departamento de lingüística}

Señor Decano:

Por la presente, me permito someterle algunas ideas sobre el Departamento de Lingüística del Instituto de Filología, que podrían eventualmente servir -si Ud. lo considerara oportunocomo base de discusión para la organización del mismo. Según he podido comprender, existiría la idea de dedicar dicho Departamento, totalmente o en gran parte, al estudio del latín o del griego y la especialización e investigación en estas materias: es decir, convertirlo en un Instituto de Letras Clásicas. Esa eventual orientación me parece inoportuna para un instituto de lingüística sudamericano, no sólo porque "Departamento de lingüística" no quiere absolutamente decir "Departamento de letras clásicas", sino también en consideración de las actuales condiciones de la investigación lingüística en el Uruguay. Yo pienso que correspondería mejor al espíritu y a las finalidades del Instituto un Departamento de lingüística general orientado especialmente a los estudios españoles, hispanoamericanos y uruguayos. En efecto, en este campo hay todavía mucho que hacer. Falta todavía una estilística española como la de Bally para el francés. Falta una gramática histórica española, como la de Nyrop para el mismo francés: es decir, más amplia y más moderna que la única que tenemos hasta ahora, la de Menéndez Pidal, todavía preciosa y muy útil, pero ya algo vieja en la concepción y el planteo teórico de tipo neogramático. Faltan estudios fundamentales sobre las relaciones entre lengua y cultura en España y en los países de habla española. Falta un estudio lingüístico de los escritores españoles que llegue por lo menos al nivel y a la amplitud de los estudios del mismo Menéndez Pidal sobre el idioma de Colón y sobre el estilo de Santa Teresa. Falta un atlas lingüístico uruguayo. Falta una gramática estructural y funcional del español. Falta una gramática de los errores, como la de Frei para el francés o la de Iordan para el rumano. Falta una fonología española y rioplatense. Faltan estudios lingüísticos y de estilística lingüística sobre los escritores uruguayos. Muy poco sabemos de la dialectología hispanoamericana (se han hecho estudios en este campo en Chile y en Argentina, pero casi nada en Uruguay). Faltan estudios sobre el argot de Montevideo y sobre el lenguaje campesino uruguayo. Faltan en general estudios sobre la fonética, la gramática y la estilística uruguayas. El estudio de los idiomas indígenas de América ha sido hasta ahora hecho casi exclusivamente por "diletantes", sin método científico. Muy poco sabemos sobre la verdadera estructura del guaraní, a pesar de las gramáticas teórico-prácticas que se han publicado hasta ahora de este idioma, y casi nada sabemos del idioma de los charrúas y de otras antiguas poblaciones de esta República. Todos estos estudios son fundamentales e imprescindibles: porque hasta ahora no se han hecho, porque pueden dar en poco tiempo resultados satisfactorios y constituir una contribución original uruguaya a la ciencia internacional y porque son los que más interesan en este país. En estas condiciones, me parece poco indicado dedicarse en primer lugar al estudio especializado del griego y del latín. En efecto, ¿cuál podría ser nuestra contribución original a la lingüística y a la filología clásicas, campos ya tan profunda y ampliamente estudiados en Alemania, en Francia, en Inglaterra, en Italia? Y ¿cuántos años serían necesarios para que se pueda alcanzar la amplitud y la especialización europeas y contribuir con algo original en estas materias? Además, ¿qué trabajo práctico, inmediatamente útil para el país, podrían desarrollar los especializados en griego y en latín? En cambio, se puede en breve tiempo contribuir con trabajos originales y útiles en los campos antedichos. No faltan los elementos capaces de llevarlos a cabo o de prepararse para hacerlo: falta sólo el método científico de la investigación y la dirección verdaderamente científica de la investigación misma. Por esto me parece poco oportuno crear 
seminarios clásicos y profundizar el sánscrito, la arqueología y las antiguas religiones del Mediterráneo, mientras, desde un punto de vista científico, no sabemos prácticamente nada sobre el habla de Maldonado, por ejemplo, o sobre la lengua de Rodó. Además, los estudios a que me refiero serían sumamente útiles como contribuciones y materiales para la linguística general. A esta disciplina de fundamental interés para el conocimiento del hombre, el griego y el latín, y el sánscrito han dado casi todo lo que podían ofrecer, mientras las lenguas vivas de América, el español americano, los idiomas indígenas de estos países, no han dado prácticamente nada de lo mucho que pueden dar.

Para subrayar el enorme interés de estos estudios, me permito señalar que en nuestra Asociación lingüística de Milán considerábamos como punto importante, en el programa a cumplir, el estudio de los idiomas indígenas americanos, y que hemos hecho, por ejemplo, estudios sobre el quechua; como también que la tendencia actual en la lingüística es precisamente la de completar el cuadro de las lenguas conocidas científicamente con el estudio de las lenguas todavía no investigadas, y de estudiar lo más profundamente y minuciosamente posible los idiomas vivos, para deducir de ellos normas y enseñanzas para la lingüística general e histórica; eso es de sorprender en el acto del desarrollo de los idiomas, para la comprensión de la evolución lingüística.

Es una idea de la vieja ciencia del lenguaje la de considerar la lingüística como ciencia de antigüedades y estudio en primer lugar de las lenguas clásicas, como lo es también aquélla de considerar la gramática española como introducción a la gramática latina y griega. Esta idea procede de un viejo prejuicio de la linguiística empírica y del error schleicheriano de considerar algunas lenguas como modelos "perfectos" y su evolución como decadencia. Hoy se considera científica la posición exactamente contraria: es decir la de considerar el latín como eventual introducción al español (y nunca el griego, con el cual el español no tiene relaciones directas de parentesco), pues la historia va del latín al español y no viceversa, y la historia es desarrollo y progreso y no decadencia. Esto desde el punto de vista histórico; mientras desde el punto de vista estructural y funcional se trata de estudios completamente distintos.

Por esto, después de los estudios de Schuchardt, Ascoli, Gilliéron, Bartoli, Bally, Vossler, Spitzer, Jespersen, las lenguas vivas se consideran como problema principal y fundamental de la lingüística y no como problema secundario y accesorio frente a los idiomas clásicos. Es verdad que la lingüística nació especialmente como lingüística clásica, pero ya hace muchos años que ha superado la época de la infancia y de la mocedad.

Estando así las cosas, me parece no sólo oportuno sino también indispensable que el Departamento de Lingüística se entienda como Departamento de linguí́stica general orientado especialmente hacia los estudios españoles, hispanoamericanos y uruguayos: la lingüística general es necesaria para el planteo y el método de la investigación, y los estudios españoles, hispanoamericanos y uruguayos son los más indicados y más urgentes en el momento actual.

Además, la lingüística general, aun siendo una ciencia independiente y aunque orientada, en nuestro caso, hacia los estudios antedichos, comprende y no excluye la lingüística clásica y los demás estudios lingüísticos ya existentes o que se podrán crear en la Facultad y en el Instituto; mientras una ciencia especial como la Lingüística clásica no comprende la lingüística general y los estudios españoles e hispanoamericanos. En todo caso, un Departamento especial de Letras clásicas podría constituir en el futuro una quinta sección del Instituto de Filología, pero no puede sustituir el departamento de lingüística. El que escribe es también latinista y de formación no sólo moderna sino también clásica, pero no deja por esto de ser realista y objetivo.

A este respecto, me parece oportuno considerar lo que se ha hecho en otros institutos similares de América. Indudablemente, el mejor instituto de filología de América del Sur es el de la Universidad de Buenos Aires, que fue por muchos años dirigido por el mejor lingüista hispanoamericano, el Dr. Amado Alonso, actualmente profesor en los Estados Unidos. Ahora 
bien: ¿Cuáles son las publicaciones de este Instituto?. La Revista de Filología hispánica y las colecciones Dialectología hispanoamericana y Estudios estilísticos. Y las obras principales del mismo prof. Alonso son: Poesía y estilo de Pablo Neruda, Problemas de dialectología hispanoamericana, El problema de la lengua en América; Castellano, español, idioma nacional, etc.: todas obras sobre el español y la lingüística y filología hispanoamericanas.

Por lo que concierne los Estados Unidos, una de las principales contribuciones de aquel país a la lingüística, la más preciosa sin duda, la constituyen las gramáticas de los idiomas indígenas de Norteamérica, publicadas por la Columbia University, y que son precisamente tesis de licenciatura y trabajos de graduados en lingüística. Así también, una de las obras norteamericanas más frecuentemente citadas y universalmente utilizadas (además de las obras de lingüística general, como la de Bloomfield o la de Sapir) es precisamente el libro de F. Boas sobre los idiomas indígenas de América.

Todas estas consideraciones confirman la oportunidad de dar al Departamento de lingüística la orientación que me permito sostener. Es indudable, pienso, que, en las condiciones actuales, los estudiantes de linguiística, los futuros trabajadores del Instituto, los futuros investigadores y profesores de lingüística nacionales que el Uruguay necesita y que el Instituto debe formar, precisan en primer lugar profundizar la moderna linguística general y aplicar sus métodos al estudio científico del enorme material que en parte conocen empíricamente, que está a su inmediata disposición y que espera su labor.

Dando esta orientación al Departamento, éste no sólo podría en breve tiempo comenzar su actividad, sino que es necesario que la inicie lo más pronto posible, para preparar para el próximo año, y en vista del trabajo a efectuar, los preliminares, los elementos y los instrumentos de investigación.

\section{Trabajo del instituto}

Según mi opinión, el Instituto no puede limitarse a ser una oficina particular de algunos profesores y sabios, quienes, pagados por la Universidad, se dediquen exclusivamente a la investigación superior, con provecho de la ciencia en general y de su prestigio personal, pero sin nigún provecho para la enseñanza en la Facultad, para la ampliación del cuerpo de colaboradores y para la preparación de nuevos elementos aptos para dedicarse a la investigación. Esto, en primer lugar, porque el número de los sabios que pueden dedicarse a la investigación es por ahora muy reducido y es preciso aumentarlo, utilizando las jóvenes energías que confluyen en la Facultad, y también porque el trabajo práctico del Instituto tiene que ser un indispensable complemento de la enseñanza ex cathedra, dada en las clases. Por esto el Instituto tiene que proponerse las dos finalidades, por el momento inseparables. Los institutos son en las facultades humanísticas como los laboratorios en las facultades de ingeniería o de medicina, en que los profesores efectúan sus investigaciones superiores pero en que, al mismo tiempo, se forman los ayudantes y colaboradores -los futuros profesores- y los estudiantes aprenden prácticamente el método y la técnica de la investigación.

Las actividades específicas del Departamento deberían ser, por consiguiente:

1. Preparar los instrumentos y los materiales indispensables para la investigación.

2. Preparar los futuros colaboradores y ayudantes del Departamento mismo.

3. Organizar trabajos prácticos individuales y colectivos sobre los problemas lingüísticos más urgentes y más indicados para el Uruguay y en este momento.

4. Publicar los mejores trabajos hechos por los profesores, con o sin la colaboración de los estudiantes y ayudantes, y también los mejores trabajos de estudiantes que demuestran especiales aptitudes para la investigación. 
5. Organizar encuestas en las ciudades y en el campo uruguayo y promover el estudio de los textos, en vista de la compilación de estudios fonéticos, semánticos, gramaticales, dialectales, etc., sobre el habla del Uruguay, el rioplatense y el español de América en general.

6. Echar desde ahora las bases para la compilación de una fonología española y rioplatense, de una dialectología uruguaya, un atlas lingüístico uruguayo, de una gramática de los errores, de una lexicografía especial uruguaya, etc..

7. Promover el estudio de los idiomas indígenas de América, mediante la exégesis crítica de las gramáticas ya existentes y la compilación de nuevas gramáticas científicas.

8. Promover, discutir y publicar trabajos lingüísticos y estilísticos sobre los mayores escritores hispanoamericanos y especialmente uruguayos.

9. Publicar ediciones críticas de los mismos escritores.

10. Publicar textos bilingües para el estudio de los idiomas clásicos y modernos, como se hace en Francia, Alemania e Inglaterra.

11. Publicar traducciones de las principales obras lingüísticas relacionadas con la metodología y la teoría glotológica general (como lo ha hecho Amado Alonso en Buenos Aires, publicando el "Curso de lingüística general" de Saussure, "El lenguaje y la vida" de Bally y la "Filosofía del lenguaje" de Vossler).

12. Publicar crestomatías lingüísticas y colecciones de textos con comentarios (latinos, griegos, romances, españoles antiguos, etc.. Un modelo de estos textos pueden ser los que publica el Instituto de Filología romance de Roma).

13. Publicar textos dialectales comentados.

14. Publicar manuales de iniciación y síntesis lingüística, originales o traducidos por profesores, estudiantes y ayudantes (entre los trabajos que se podrían traducir: Die Haupttypen des Sprachbaus de Finck, Die Sprachstämme der Erde de Kiekers, Fonetica generale de Battisti, Introduzione alla linguistica indoeuropea de Pisani, Introduzione allo studio delle lingue germaniche del mismo, Romanische Sprachwissenschaft de Zauner, Germanische Sprachwissenschaft de Loewe, Geschichte der lateinischen Sprache de Stolz y Debrunner, Aperçu d'une histoire de la langue grecque de Meillet, La linguistique de Marouzeau, Lexique de la terminologie linguistique del mismo, etc., etc.).

15. Discutir y publicar los cursos linguiísticos monográficos de los profesores de la Facultad.

16. Organizar discusiones sobre temas lingüísticos.

17. Organizar conferencias lingüísticas de profesores uruguayos y extranjeros.

18. Organizar convenios lingüísticos uruguayos e hispanoamericanos.

19. Publicar textos gramaticales para la enseñanza universitaria y secundaria.

20. Publicar una revista trimestral, semestral o anual de lingüística. 
21. Organizar un centro o una asociación de estudios lingüísticos, integrada por profesores, estudiantes, ayudantes y hasta personas extrañas a la Facultad que se interesen por estos estudios.

22. Organizar sesiones periódicas para la lectura y la discusión crítica de los trabajos presentados para la publicación en la revista del Departamento.

23. Estar a disposición de los estudiantes e investigadores para toda información bibliográfica y metodológica.

24. Colaborar con el Departamento de Folklore para el estudio lingüístico de los textos por aquél recogidos.

25. Colaborar con los Departamentos de Literatura española y Literatura iberoamericana para el estudio del aspecto lingüístico de los textos literarios españoles e iberoamericanos.

Todo esto, desde luego, sólo gradualmente y con la consideración realista de las posibilidades del Instituto y de las necesidades inmediatas de la enseñanza.

\section{Lecciones de instituto}

Las clases puramente expositivas, ex cathedra, son indudablemente insuficientes para una verdadera especialización y para la selección de los elementos aptos para la investigación.

En efecto, en las clases expositivas, los estudiantes aprenden teóricamente una materia, o una sección monográfica de una materia, pero no la práctica de la investigación en la misma: aprenden las conclusiones, las síntesis a que ha llegado el profesor, pero no el método con que ha llegado a ella. Además, la selección de los estudiantes no se puede de ninguna manera hacer en estas clases, como tampoco se puede hacer en los exámenes, en que se comprueba sólo si los estudiantes saben lo que el profesor ha expuesto y lo que han debido estudiar por su cuenta, pero no si saben o no investigar.

Se precisa por esto instituir clases de seminario o de institutos, en que el profesor se encuentre en más directo e íntimo contacto con los estudiantes. En estas clases, el profesor no expondría conclusiones, no presentaría un trabajo ya hecho, sino desenvolvería el trabajo bajo los ojos de los estudiantes y con su colaboración, discutiendo con ellos e indicándoles las dificultades, el método y la técnica del trabajo. En estas clases -que no se confundirían con la actividad específica del Instituto, pero estarían estrechamente relacionadas con ella- los estudiantes aprenderían a utilizar los libros, a buscar las indicaciones bibliográficas, a estudiar prácticamente los textos, a efectuar trabajo de archivo, a compilar ficheros, etc..

La llamo clases "de instituto" porque deberían efectuarse en los locales del Instituto, donde tanto el profesor como los estudiantes tendrían a su disposición los instrumentos de trabajo, los libros, las revistas, etc..

En las mismas lecciones, el profesor propondría a los estudiantes temas a desarrollar en trabajos escritos, que se leerían después y se discutirían críticamente en las mismas clases, no sólo por el profesor sino también por los estudiantes. Estos trabajos, asignados por el profesor, según la capacidad y la preparación de los alumnos, podrían ir de los simples resúmenes y de las recensiones, a la comparación de dos o más textos, a la exposición crítica de las ideas de un autor, a la investigación personal de temas ya estudiados o todavía no investigados. En las clases de Instituto, los estudiantes aprenderían de esta manera verdaderamente y prácticamente el método y la técnica de la investigación, mediante las dificultades que encontrarían en el desarrollo de sus trabajos y mediante la discusión crítica de los mismos. Los mejores de estos trabajos se publicarían en los "Cuadernos de estudiantes" y, en casos excepcionales -que no podemos excluir, sino, al contrario, tenemos que desear- 
también en la revista del Instituto o en la misma revista de la Facultad. De esta manera, los estudiantes podrían empezar su eventual carrera científica desde los años de universidad y, por otra parte, el profesor podría proceder a la preparación y selección de los elementos aptos para la investigación superior y para las actividades específicas del Instituto: sus futuros ayudantes, colaboradores y sucesores en la enseñanza.

Así, por lo menos, se conciben las clases de instituto o seminario en los Institutos europeos que yo conozco. Y pienso que no tenemos porqué alejarnos de un modo que ha demostrado magníficamente su utilidad.

Con la esperanza de que estas ideas puedan servir por lo menos como sugerencias y premisas para la discusión de las comisiones competentes, saludo a Ud. muy atentamente. (FDO.), Eugenio Coseriu. ${ }^{1}$

1 Al final del documento aparece la fecha añadida entre corchetes [1949]. En vistas a la biografía de Coseriu, esta fechación parece imposible. Realmente es más probable que el texto date de 1950, año de la llegada de Eugenio Coseriu al Uruguay. 
Eugenio Coseriu

\section{Algunos preliminares para una discusión concreta [1950]}

Desgraciadamente, en la segunda reunión han vuelto a discutirse puntos que podíamos considerar establecidos después de la primera reunión y a expresarse opiniones que considerábamos dialécticamente eliminadas: evidentemente, existe la tendencia a no cambiar nada, a dejar las cosas como están y esto no porque el actual plan de estudios sea perfecto o bueno -nadie podría afirmarlo- sino por motivos que yo -por lo menos- no logro comprender. Vds. querrán perdonarme si yo, invitado por el señor Decano a participar en estas reuniones, he tomado en serio la tarea de estudiar la reforma del plan de estudios y me permitiré por lo tanto, basándome en mi experiencia de docente de una universidad europea y en la observación del ambiente uruguayo, expresar ideas contrarias a muchas de las que se han expresado aquí en la última reunión.

1. Vuelvo a repetir mi concepto fundamental, es decir que para establecer un plan de estudios racional y realista hay que considerar en primer lugar las finalidades del estudio en esta facultad y en segundo lugar las condiciones reales (alumnado, profesores, posibilidades financieras) que se nos ofrecen.

¿Cuáles son las finalidades del estudio en una Facultad de Humanidades? Las del estudio en general, es decir la especialización y la investigación.

La especialización impone necesariamente la distinción de las licenciaturas, pues el campo de las Letras es enormemente vasto: es muy difícil, si no imposible, crear licenciados que sean especializados en letras clásicas y al mismo tiempo en letras modernas, en estudios lingüísticos y al mismo tiempo literarios. Discutamos, pues, concretamente: han sido propuestas tres licenciaturas. ¿Son posibles las tres en las actuales condiciones? ¿O no? De todo modo, hay que recordar que el plan que discutiremos aquí no será el definitivo: constituirá sólo un conjunto de sugerencias para la omisión encargada de la reforma del plan de estudios. Y tampoco será definitivo el plan que establecerá la comisión: en las actuales condiciones no podemos tener la ambición de establecer un plan definitivo. Estableceremos, pues, un plan provisorio, pero mejor que el actual y que contenga las premisas del plan definitivo, es decir que sea fácilmente reformable ulteriormente. Se podrían, por consiguiente, proyectar dos licenciaturas efectivas y una eventual, delineada desde ahora, aunque no definitivamente.

La investigación impone la distinción de las clases en teóricas y prácticas (clases de seminario o de instituto) y también la limitación de las asignaturas a las materias absolutamente indispensables, imprescindibles para cada licenciatura proyectada. No incluyamos en el plan demasiadas materias obligatorias ni materias demasiado generales. ¿Dónde se enseñan las materias introductivas y todas las materias especiales de que se ha hablado aquí la vez pasada? En ninguna parte del mundo, según lo que me resulta. Muchas de las materias especiales y generales se enseñan en las universidades europeas en las asignaturas fundamentales, prácticamente, en las clases de seminario, y gradualmente, mediante el trabajo en continuo contacto con el profesor. Consideremos, por ejemplo, el caso de Italia: en Italia las materias obligatorias para graduarse en Letras son 17, de las cuales tres bienales. Este 
número puede aparecer insuficiente para una verdadera especialización. En efecto, yo mismo, queriendo especializarme realmente en lingüística general, romance y eslava, hice no 17 materias sino 38, según resulta de los documentos entregados a esta secretaría. Sin embargo, hay que considerar que las materias que se consideran indispensables para un licenciado en Italia, es decir para una persona que posea la técnica de la investigación y los fundamentos de la investigación misma, son sólo 17 y que muchas de las materias que se han propuesto aquí no se enseñan ni en la Facultad de Letras de Roma, cuyo plan contiene unas setenta materias. Yo, como he dicho, he hecho mucho más de lo estrictamente indispensable, pero confieso no haber nunca hecho algunas de las materias que se han sugerido aquí como indispensables.

La Facultad, en efecto, no puede dar a los estudiantes una cultura general, si ya no la tienen, no puede transformarse en un ateneo libre, en una especie de liceo superior, y aumentar indefinidamente el número de las materias obligatorias. Por esto, muchas materias no aparecerán en el plan de estudios, lo que, naturalmente, no significará que los profesores deberán ignorarlas en sus clases o en las listas de obras cuya lectura recomendarán y exigirán a los estudiantes. He aquí algunas de estas materias: Historia de las religiones, Historia del Cristianismo, Mitología, Lógica, Filosofía, Literatura hebrea o Exégesis bíblica, Cultura asiro-babilonesa, Lengua y literatura árabes etc. Todas materias muy importantes, pero que no se pueden hacer por ahora.

La Historia de las religiones, por ejemplo, puede aparecer fundamental, pues la actitud teológica es una actitud primordial del hombre. Sin embargo, no es una materia indispensable para la licenciatura en letras: cuando haya referencias religiosas en cualquier materia, el profesor podrá hacerlas sin recurrir a un estudio especializado. Así también la Historia del Cristianismo: toda la cultura occidental después del clasicismo y hasta Santo Tomás es una cultura cristiana, pero el cristianismo es sólo el motivo fundamental de esta cultura y no se confunde con la cultura misma. Por esto, por ahora y en un plan de estudios mínimo, podemos renunciar al estudio del cristianismo como fenómeno puramente religioso y autónomo. También la Mitología puede aparecer muy importante: toda la literatura española, por ejemplo, está llena de referencias mitológicas. Pero no me parece indispensable un estudio especializado de esta materia, que ella también pertenece a la cultura general. Las referencias necesarias las hará en el curso de su trabajo el profesor respectivo. Así, por ejemplo, encontrando en El condenado por desconfiado de Tirso de Molina el nombre Amalton, el profesor de español dirá que se trata de una cabra mitológica que alimentó a Júpiter, sin precisar por esto estudios mitológicos especializados y sin exigirlos a los alumnos. Si en $L a$ Gatomaquia de Lope de Vega se encuentra un verbo piramizar, el profesor explicará que se trata de un verbo creado por el mismo Lope con alusión a la leyenda de Píramo y Tisbe. Si en la soledad primera de Góngora se habla del "mentido robador de Europa", el profesor explicará que se trata de Júpiter y recordará a los alumnos la leyenda mitológica etc.

La Lógica es una ciencia fundamental y es fundamental hasta la lógica clásica, aristotélica. En efecto, no obstante las reformas de Leibniz y de Hegel, las críticas de John Stuart Mill y las de los matemáticos, como Frege o Russell, no obstante la constitución de una nueva lógica, toda nuestra metodología está todavía basada, por lo menos en gran parte, sobre la lógica aristotélica. Sin embargo, yo no pido que se enseñe Lógica en la sección de Letras: la lógica no puede faltar en la cultura general del enseñante y, tratándose de cuestiones muy especiales, se podrá recurrir al respectivo profesor de la sección de Filosofía, como también por la Filosofía en general. La Literatura hebrea es muy importante, pues no se puede concebir una 
cultura general sin el conocimiento de la Biblia, pero ¿podremos nosotros exigir que estudien exégesis bíblicas los alumnos que quieren ocuparse de latín o de español? Además, si se profundizan un poco las cosas, se verá que los mitos bíblicos son en gran parte, como la ciencia y los descubrimientos contemporáneos están estableciendo, de origen asiro-babilonés. ¿Tendríamos, entonces, que ocuparnos también de cultura asiro-babilonesa y dedicarnos a descifrar textos cuneiformes, mientras tenemos tantas cosas que estudiar en el campo español, iberoamericano y uruguayo?

Otra materia de enorme importancia, especialmente en un país de habla española: Lengua y literatura árabes. Todos saben que los árabes fueron el vehículo que llevó a Europa la cultura griega, en gran parte, por lo menos hasta el Renacimiento, y también la cultura persa (son, en efecto, persas los mayores filósofos que llamamos “árabes"). Pero para España y para los países de habla española la importancia de los árabes es todavía mucho más importante. La dominación árabe en España dura -si me equivoco ruego a los profesores de historia que me corrijan- de 711 (batalla del Guadalete) a 1492 (reconquista de Granada), es decir 761 años, casi ocho siglos: más que de Numancia a las primeras invasiones de suebos y vándalos. La influencia de los árabes en la cultura española es, como todos saben, enorme. Por lo que concierne las materias de mi especialización puedo observar que con sólo leer El idioma español en sus primeros tiempos de Menéndez Pidal uno podrá darse cuenta de la enorme importancia que tienen los documentos árabes para la historia de la lengua española y que en la filología romance existe una teoría árabe de la poesía europea. ¿Pero podremos nosotros hacer seriamente estudios árabes? Según me resulta, estos estudios tan importantes no se hacen ni siquiera en todas las universidades españolas: no sé si mi información falla, pero yo conozco un solo gran arabista español, Asín Palacios. ¿Qué haremos, entonces? Por ahora nos conformaremos con que los profesores respectivos se informen y hagan las referencias árabes, cuando las encuentren necesarias.

Lo mismo se podría decir de muchas otras materias. Es verdad que el espíritu es uno solo, pero todas las actividades humanas y todas las ciencias, de la matemática a la medicina y a las técnicas, pertenecen de alguna manera al espíritu y en ninguna facultad se puede enseñar todo el contenido del espíritu. Hoy ya no es posible el "hombre universal" como Leon Baptista Alberti o como Pico della Mirándola y hasta como Leibniz. Además, para volver a hablar concretamente, ¿podríamos nosotros hacer todos los estudios antedichos en las condiciones actuales? ¿Tenemos acaso los profesores necesarios? ¿Tenemos las posibilidades financieras? Evidentemente, no. Bueno: entonces adaptémonos a las condiciones concretas, a las finalidades concretas del estudio y a las necesidades concretas e inmediatas del país. No hablemos de utopías, de grandes clasicistas, de grandes especialistas en disciplinas clásicas, pues ni los licenciados deben ser tales ni nosotros, francamente, podemos hacerlos tales. En todo caso, si es necesario enseñar más, aumentemos las horas de clase, no los años de estudio, lo que serviría sólo a asustar a los estudiantes y a disminuir todavía más su número, que no es conspicuo.

Y no propongamos que se enseñen en la Facultad materias de secundaria y tan elementales como la gramática castellana. La gramática pertenece a la cultura general de las personas cultas y yo no puedo creer que haya verdaderamente estudiantes de letras que no saben gramática o que no hayan estudiado gramática. En efecto, quiero recordarles que para emplear bien un idioma no es necesario tanto saber gramática como haber estudiado gramática. La gramática es una cosa que (esto no hay que decirlo a los estudiantes, pero 
podemos decirlo entre profesores) hay que aprenderla para olvidarla, pues la lengua no es sólo una cuestión de gramática sino también de gusto, de sentido estético. No digamos que los estudiantes no saben gramática sólo porque ignoran la terminología gramatical, mientras empleen bien el idioma. No olvidemos que la gramática no es la lengua sino un esquema artificial que se impone a la lengua real, viva y que no es una cosa que existe antes sino que se hace después de la lengua: no es Cervantes quien debe obedecer a la gramática sino la gramática que tiene que obedecer a Cervantes. Y les hago notar que estas cosas las dice un lingüista, es decir un gramático y que no se trata de opiniones sino de conclusiones de la lingüística moderna, de la misma gramática moderna. En todo caso, si por conocimientos gramaticales se entiende el conocimiento de la teoría gramatical o, mejor, la terminología gramatical, el problema no es tan grave como para instituir una enseñanza de la gramática castellana en la Facultad, pues presenta dos soluciones mucho más sencillas: los profesores pueden muy bien enseñar a los estudiantes la terminología necesaria, en las mismas clases de griego o de latín, lo que no llevaría demasiado tiempo, o organizar clases suplementarias para los estudiantes que "no saben gramática". Además no olvidemos que en el mismo plan actual existe una norma muy razonable sobre este punto: la que establece que el profesor puede exigir a los estudiantes que presentan deficiencias en el empleo del idioma nacional nuevos estudios de este idioma.

En todo caso, no se puede hablar de la gramática griega y latina, pues esto constituiría un grave error desde el punto de vista lingüístico. En efecto, no podemos considerar la gramática castellana como introducción a las gramáticas latina y griega pues se trata de sistemas, de estructuras lingüísticas distintas y uno de los errores más graves que pueda hacer el lingüista o el pedagogo es el de aplicar a una lengua el molde, la gramática de otra lengua. Si nuestra gramática es todavía en gran parte absurda, lo es precisamente porque por siglos se le ha aplicado el molde de la gramática latina y si no tenemos gramáticas científicas de los idiomas indígenas de América es precisamente porque se ha querido aplicar a estos idiomas la gramática castellana o la misma gramática latina. Si nuestra terminología gramatical es en gran parte absurda, es porque se ha traducido mal del griego al latín o porque se ha aplicado también al latín mientras convenía sólo al griego. Así, por ejemplo, nosotros llamamos genitivo un caso gramatical que no indica el origen, la proveniencia, y esto porque el lat. genitivus fue una mala traducción del gr. geniké, derivado de génos, que indica más bien la forma, el modo y no el origen. Llamamos acusativo un caso que no acusa, sólo porque el griego aitiatiké se interpretó en latín como derivado de aitiáomai (acusar, denunciar) y no de aitiatós (impulsado, forzado), como era en realidad. Nosotros llamamos acento (de adcantum) un fenómeno fonético que no tiene nada que ver con el canto, sólo porque en latín se tradujo literalmente el griego prosodia (de pròs odén), "entonación", que correspondía muy bien al acento griego, que era efectivamente musical, melódico. No hagamos, pues, más errores como estos, sobre todo pudiendo, como podemos, evitarlos. Y por lo que concierne a la gramática práctica castellana, no exijamos a los estudiantes su estudio si emplean bien el idioma, pues la gramática vale precisamente como norma ideal para el empleo de un idioma y cuando este empleo es satisfactorio no investiguemos si la norma se conoce verdaderamente o se conoce todavía o se ignora, porque ha sido asimilada: el gusto, el sentido del idioma valen mucho más que unas pocas reglas artificiales y a veces absurdas, aprendidas de memoria, como es la que en castellano existe la declinación, mientras, como bien decía el prof. Pereira Rodríguez este es un fenómeno que la estructura gramatical española ignora totalmente en los 
sustantivos y conoce sólo en los pronombres personales. Ojalá se llegara al mismo gusto, al mismo sentido de la lengua en griego y latín, es decir a que los estudiantes ignoraran la gramática, pero supieran leer e interpretar cualquier trozo griego o latino.

2. Recordemos, en segundo lugar, la finalidad de estas reuniones: discutir un plan de estudios para el 1951 y no reformar la Facultad. Las ideas que aquí se han expresado podrán ser muy útiles también para una reforma de toda la Facultad o, por lo menos, de la Sección Letras, pero, objetivamente, quedan afuera de las finalidades inmediatas de nuestras reuniones. No discutamos, pues, la cuestión de los preparatorios ni el aumento de los años de estudio. Supongamos que el año que viene las cosas -como es muy probable- queden exactamente como están ahora y discutamos un plan mejor y mejorable en estas condiciones concretas. Tendremos tiempo de discutir un nuevo plan si se llegara a conseguir los preparatorios.

Además: ¿son verdaderamente necesarios más años? Se ha hablado especialmente de aumentar los años para las lenguas clásicas y yo me pregunto por qué hablamos tanto de las lenguas clásicas mientras se trata de las disciplinas que -con cuatro años cada una- son las que se encuentran mejor en el actual plan de estudios, mientras lo que hay que reformar es precisamente lo demás. $\mathrm{Y}$ ¿es verdaderamente necesario aumentar los años para las disciplinas clásicas? Y ¿cuál será el resultado útil para el país de una mayor especialización clásica, mientras no tenemos suficiente número de especializados en disciplinas algo más urgentes, como la literatura española, la literatura iberoamericana, la literatura uruguaya, la lingüística española o hispanoamericana? Yo comprendo que cada profesor afirme la fundamental importancia de su materia, pero hay que pensar que nosotros tenemos que crear licenciados capaces de investigar en distintos campos, personas que conozcan la técnica y los instrumentos de la investigación (en las distintas ramas de las letras y no sólo en disciplinas clásicas) y no grandes sabios, grandes especialistas. También para historia serían necesarios más años, y para filosofía, para francés, italiano etc. No sólo las disciplinas clásicas son vastas. Al contrario: desde un punto de vista objetivo y puramente material, cuantitativo, hay materias mucho más vastas: la literatura italiana, y la francesa, y la española son mucho más vastas que la literatura clásica latina y la historia es, desde luego, mucho más vasta que el griego y el latín juntos. Con todo, no se han pedido más años de francés, italiano o historia.

Por lo que concierne la dificultad de las disciplinas clásicas, me permitiré contestar desde un punto de vista lingüístico, negativamente. Las lenguas clásicas no son más difíciles que las lenguas modernas. Son lenguas como las demás. No sólo: las hay mucho más difíciles, como el polaco o el ruso, si dificultad quiere decir sistema gramatical complicado. Frente a estas lenguas, el latín y el griego son lenguas relativamente fáciles. $\mathrm{Y}$ hasta lenguas que nos parecen muy sencillas son más difíciles que las lenguas clásicas bajo cierto aspecto. Así, por ejemplo, desde el punto de vista fonético, el francés y el inglés -que tienen respectivamente 16 y 14 vocales- son más difíciles que el latín -que tenía sólo cinco, en su época clásica-. Y no hay quien diga que lenguas como el ruso, el polaco, el francés o el inglés no se puedan aprender en dos años. Yo estoy convencido de que, con cinco horas de clases semanales, cualquier lengua se aprende en dos años, sobre todo si no se trata de hablarla sino sólo de leerla. Por esto, no nos dejemos conquistar por un complejo de inferioridad frente a los idiomas clásicos. En Europa se han estudiado estos idiomas durante siglos como disciplinas fundamentales y siempre con muchas horas semanales y por muchos años lo que ha creado el mito de su dificultad: es, justamente, este mito que tiene ahora sus efectos en América. 
Se ha hablado aquí del latín de Bergson. Voy a dar otro ejemplo: Erasmo aprendió el griego en un año. El ejemplo puede parecer absurdo, pues no todos los estudiantes tienen la capacidad mental de Erasmo. Pero nosotros damos a nuestros estudiantes no un año solo sino cuatro y, además, no les exigimos que salgan Erasmos; nos conformarímos que salieran "erasmitos"... Lo importante no es aumentar los años de estudio, sino enseñar bien e intensamente, lo que se puede hacer muy bien con 5 horas semanales en los primeros dos años y con dos horas prácticas de lectura de textos (además de las 3 de literatura) en los últimos dos años.

Otra cosa: no nos dejemos conquistar por un complejo de inferioridad frente a la cultura clásica: esta cultura no nos es ajena, es nuestra misma cultura, en una fase anterior y es por esto siempre presente en nuestro espíritu. Este no es un país primitivo, surgido sobre las viviendas charrúas, sino un país europeo, con población europea. Por esto la cultura europea es nuestra cultura y aun los mayores enemigos del clasicismo en este país -si los hay- son, en cierto sentido, de formación implícitamente clásica, aunque lo ignoren. Pero recordemos que nuestra cultura estriba en la cultura clásica y no en los idiomas clásicos: el contacto con la cultura clásica se puede establecer muy bien -y quizás mejor- aun sin conocer los idiomas clásicos. En efecto, yo creo que nuestros estudiantes, si no se dedican especialmente al griego, nunca van a ser capaces de leer o interpretar a Esquilo, por ejemplo, como un gran filólogo especialista de griego. Entonces, tanto valen que, si el estudiante no se dedica especialmente y profesionalmente al griego, las buenas traducciones, que presentan mayores garantías de las que podría presentar una interpretación suya del texto original. Por esto yo no comprendo la necesidad de enseñar los idiomas clásicos (no la cultura clásica, que es otra cosa) en las licenciaturas modernas, a no ser el latín, que no es necesario como fase anterior del español, es decir para comprender la historia de este mismo idioma que se llama castellano o español y que es una forma actual del latín, el aspecto que el latín tiene en Castilla o en las orillas del Río de la Plata, como son formas actuales del latín el francés, el italiano, el portugués, el rumano, el catalán, el provenzal. No es indispensable, en cambio, el griego, que no tiene relaciones directas de parentescos con nuestros idiomas modernos.

Además no olvidemos que el demasiado amplio estudio clásico podría quitarnos las posibilidades de organizar suficientemente los estudios de los campos que nos interesan más directamente y urgentemente y que han sido insuficientemente estudiados: literatura española, literatura iberoamericana, literatura uruguaya, lingüística española, lingüística hispanoamericana etc. Quiero hacer notar, por lo que concierne más directamente la lingüística, que -si se excluye el portugués- el español es el idioma menos estudiado entre todos los idiomas romances. (El más estudiado es el francés; siguen el italiano y, por razones especiales, el rumano).

Recordemos asimismo que los cuatro años propuestos son un mínimo teórico, que puede subir a cinco o a seis, mediante los pasajes de curso o los exámenes (que, además, garantizarían mejor la seriedad del estudio $y$, si por casualidad fuera necesario, la absoluta imparcialidad de los profesores).

3. Y ahora una cosa un poco delicada: yo pienso que habría que terminar con la absurda y odiosa comparación con Europa. Está de decir que con Europa -para parafrasear un slogan político-"no hay quien pueda", que en Europa se estudia mejor, que sólo en Europa se estudia, que sólo en Europa se estudian bien las lenguas clásicas etc. es una costumbre que 
hay que reprobar. Yo la comprendo muy bien en los inmigrantes (y con esta palabra no pienso ofender a nadie: yo mismo soy un inmigrante, y de fecha muy reciente) que viven todavía en sus ambientes más o menos europeizantes y no se mezclan lo suficiente con el ambiente vivo del Uruguay, los inmigrantes de la primera generación, en los primeros tiempos después de su llegada al país, es una forma de su nostalgia y constituye además su afirmación de superioridad y su defensa. Pero lo malo es que esta actitud haya conquistado también a muchos uruguayos, que se han dejado dominar por un complejo de inferioridad frente a Europa. Ahora bien, si esta actitud es admisible y humanamente comprensible, ella no puede y no debe ser la actitud de los uruguayos y de los inmigrantes que queremos ser uruguayos y trabajar para este país, en las condiciones que este país nos ofrece y con las finalidades que estas condiciones imponen. Y esto no por una razón de gratitud hacia este país que nos acepta a todos -sin hacer distinciones de nacionalidad, de raza, de religión o de clase social- sino por una razón de objetividad. Vemos si el Uruguay no puede realmente sobrellevar la comparación objetiva con Europa. Es verdad que en el Uruguay no se hacen suficientes estudios clásicos, y esta es una falta que hay que eliminar. Pero los estudios clásicos no son todo: se hacen, en cambio, en el Uruguay muchas cosas que en Europa no se hacen o no se hacen lo suficiente. Para darse cuenta de esto, alcanza no encerrarse en las nostalgias europeas $\mathrm{y}$ en prejuicios acerca de las posibilidades reales del ambiente uruguayo, sino observar concretamente y atentamente este ambiente, observar, por ejemplo, que en Montevideo hay más librerías que en Roma, una ciudad mucho más grande y más importante culturamente. Yo invitaría a los nostálgicos desconfiados a observar la vidriera de una librería montevideana y decirme si se ven en las librerías europeas todos los libros que encontramos aquí, si se encuentran, por ejemplo, en las librerías italianas traducciones tan completas de Dilthey, Casirer, Simmel, Russell etc. Y todo esto es cultura y cultura que alguien asimila, porque estos libros se leen, mientras en Italia los leen sólo los especialistas y unas pocas personas más, pues no están traducidos. Por lo que concierne la lingüística, cada lingüista informado habrá notado que se encuentran traducidas al español muchas obras fundamentales que nunca se han traducido al italiano. He aquí algunas de ellas: V. Thomsen, Historia de la lingüística; W. Meyer-Lübke, Introducción a la lingüística romance; J. Vendryes, El lenguaje; Ch. Bally, El lenguaje y la vida; K. Vossler, Filosofía del lenguaje; J. Stenzel, Filosofía del lenguaje; F. Kretschmer, Introducción a la lingüística griega y latina; F. De Saussure, Curso de lingüística general; A. Dauzat, Filosofía del lenguaje etc. etc. Todos estos libros no se encuentran en italiano, mientras han sido traducidos al español y se encuentran en nuestras librerías normales, mientras en Europa libros de este género se encuentran generalmente sólo en librerías especializadas. Y estos libros se venden, alguien los lee. Faltan los lingüistas en el Uruguay, pero no falta el interés por la lingüística: esta es la realidad que debemos tener en cuenta. Esta es la realidad de una comparación objetiva con Europa. Por consiguiente, me parece que no debemos exagerar con la "autoflagelación" frente a la superioridad europea, que todos reconocemos objetivamente en los campos en que la tiene realmente.

Yo pienso por esto que nuestra actitud tendría que ser la de los Estados Unidos, una actitud que, mientras estaba en Europa, me parecía a mi también algo antipática, pero que ahora comprendo perfectamente: los norteamericanos, en general, ignoran formalmente Europa y continúan trabajando como si Europa no existiera. Y es la única manera de hacer algo sólido y serio: si vivimos siempre amenazados por el espectro de la indudable 
superioridad europea, nunca podremos hacer nada, pues siempre nos resultará que "en Europa lo hacen mejor".

4. Así también me parece que no deberíamos asustarnos por las palabras. La semántica moderna ha demostrado que las palabras no tienen un sentido inmutable, sino el sentido convencional que se les quiere dar. Por esto el nombre por mi propuesto -"filología clásica"no me parece demasiado pomposo. Interviene aquí otro prejuicio de la vieja lingüística, especialmente alemana, que se vuelve un prejuicio para los estudios: el de distinguir netamente la filología de la lingüística. Sabemos que esta distinción ya no la hacen más lingüistas tan ilustres como Vossler o Spitzer. Además, desde el punto de vista metodológico y pedagógico el contacto entre filología y lingüística es muy recomendable. En efecto, "filología" puede significar la ciencia de todas las informaciones que se deducen de los textos $\mathrm{y}$, en este caso, la filología es historia cultural, social, religiosa, literaria etc. Pero el mismo término tiene un sentido más limitado y tradicional de "crítica de los textos", y en este sentido conviene emplearlo. En mi proyecto incluí las disciplinas "Filología clásica" y "Filología romance" porque entiendo que en estas asignaturas se haga algo más que pura lingüística: que en Filología clásica se haga lingüística concreta, sobre los textos, se estudie el latín y el griego en sus varias formas literarias como en su historia gramatical y estilística, en relación con la historia cultural, y que en Filología romance se haga no sólo gramática comparada de las lenguas romances sino también literaturas romances antiguas (francesa, italiana, provenzal, gallego-portuguesa) y, en ciertos casos, también literaturas modernas, si para estas literaturas no existen asignaturas especiales (p.ej. portugués).

5. Los años de estudio pueden aparecernos insuficientes sólo si pensamos que el estudio clásico debe hacerse en su integridad en las asignaturas de latín y griego. Pero así no es, ni sería posible hacerlo. Hay, en efecto, otras materias que completan el estudio del griego y del latín. La señora de Scazzocchio me decía hace algunas semanas -y, para no equivocarme, quiero repetir sus mismas palabras- que ella, en los últimos años, ya no hace griego sino gramática comparada e indoeuropea. Y yo encuentro que está muy bien que lo haga, pues por ahora no se dictan en la facultad lingüística clásica y lingüística indoeuropea. Pero yo no puedo pensar que la Señora de Scazzocchio enseñe gramática comparada mientras los estudiantes no dominan suficientemente el griego, pues, desde un punto de vista lingüístico y pedagógico, éste sería un contrasentido. En efecto, es un grave error el de enseñar una lengua mediante la lingüística, pues la lingüística no es estudio práctico de los idiomas, sino investigación científica. Puede ser útil para el estudio de los idiomas, pero sólo al lingüista, que puede establecer las comparaciones respectivas, y no al principiante y tampoco a un estudiante de tercer año. En la enseñanza humanística de los idiomas, la lingüística es un peligro y no una ayuda: su tarea puede ser sólo la de explicar racionalmente algunos detalles o la de impedir errores -impedir que se diga, por ejemplo, como se decía un tiempo, que el latín deriva del griego y ambos del sánscrito-. Y, como yo no puedo absolutamente pensar que una profesora tan eminente como la Señora de Scazzocchio haga un error tan grave, tengo que deducir que en los últimos años, es decir en el $3^{0}$ y $4^{0}$, sus estudiantes ya saben prácticamente el griego. Esta deducción queda confirmada por la otra afirmación de la Señora de Scazzocchio, es decir que en los últimos años algunos de sus estudiantes ya pueden leer textos 
griegos, si no muy difíciles bastante difíciles, como Platón, y corresponde a mi convicción intimada que, en efecto, enseñando bien, en dos años se puede enseñar mucho.

Ahora bien, si en dos años con tres horas semanales se han logrado estos resultados, en el mismo número de años con 5 horas semanales se lograría mucho más. No sólo: los años no serían dos sino cuatro, pues en los últimos dos años, mientras en las clases teóricas se haría literatura, en las clases prácticas se continuaría profundizando el idioma, mediante la lectura de trozos literarios. Con esto, la amplitud de los estudios sería casi igual a la de Europa. En Italia, por ejemplo, se hacen cinco años de griego en el liceo, con 3 horas semanales, y 2 en la Universidad (sólo de literatura y sólo para los estudiantes de la sección clásica), también con 3 horas semanales: es decir que, calculándolo todo en un año, tendríamos un total de 7 x $3=$ 21 horas semanales. Nosotros tendríamos en cambio 4 x $5=20$ horas semanales, es decir sólo una hora menos que en Italia, lo que no me parece poco, dadas nuestras condiciones y necesidades.

Además, en las asignaturas de griego y latín, según los proyectos presentados, la enseñanza se limitaría exclusivamente al estudio de los idiomas y de las respectivas literaturas, mientras el mismo estudio se completaría lingüísticamente en otras asignaturas. En lingüística clásica, los estudiantes aprenderían la historia del latín y del griego, la posición de estos dos idiomas frente a los idiomas mediterráneos preindoeuropeos, la posición del latín entre los dialectos itálicos, la dialectología griega, la historia del griego en el período sucesivo a la koiné, hasta el bizantino y el neogriego etc. En lingüística general e indoeuropea, aprenderían la comparación de los mismos idiomas con el sánscrito y los demás idiomas indoeuropeos. En linguiística romance aprenderían el latín popular y su historia en la Edad media y moderna, hasta los idiomas romances actuales. En lingüística española, aprenderían la historia de una parte del latín popular hasta el latín actual de Castilla -o español- y el latín actual de Montevideo. Me parece que sería un estudio bastante completo.

Pero quiero admitir que aun con esta ampliación del estudio algunos estudiantes no llegarán a conocer bien el latín y el griego. En este caso, la solución es una sola: no el aumento de los años de estudio, sino clases suplementarias para los estudiantes que no logran cumplir con el programa. Estas clases las haría por ahora el profesor mismo y en el futuro los ayudantes, cuando los haya.

Se ha dicho que los estudiantes "prefieren" el aumento de los años de estudio. Yo creo que no podemos afirmar esto hasta no haber consultado los estudiantes pues me resulta exactamente lo contrario: todos los estudiantes con que he tenido ocasión de hablar, se me han declarado adversarios del aumento del mínimo teórico de los años de estudio. ¿Por qué impedir que alguien, pudiendo, termine la facultad en cuatro años? Ya los tendremos a los que, por tener una ocupación o por otras razones, tendrán que hacer más años.

6. Otra cosa: se ha dicho que la distinción de las licenciaturas sería prematura. No lo creo: el hecho mismo de que se hayan convocado estas reuniones quiere decir que la necesidad de una reforma se impone, pues admitir que la reforma es prematura sería admitir que el plan actual está bien y seguir con cuatro años de griego y latín y un solo año de español y ninguno de lingüística española, es decir continuar con una facultad reducida prácticamente a una licenciatura clásica -lo que me parece no sólo inútil sino también absurdo y absolutamente inadmisible. 
7. Se ha hablado también de otra razón para no distinguir las dos licenciaturas, que, según pienso, debería ser la razón principal: el temor que, habiendo en la facultad letras modernas, los estudiantes dejen de estudiar letras clásicas. Yo no creo, sin embargo, que este miedo pueda tener una base real, pues actualmente la Facultad es casi exclusivamente clásica y, a pesar de ello, tiene bastante estudiantes, que no se asustan de los cuatro años de griego y latín. Al contrario, la distinción de las licenciaturas aumentaría el número de los estudiantes, pues vendrían a la Facultad también aquellas personas que desearían estudiar letras modernas solamente, pero no cuatro años de griego y latín. Además, no podemos organizar la facultad basándonos sobre este temor, aun cuando fuera justificado, no podemos darles a los estudiantes como "añadidura" el español que quieren sólo para que estudien también griego y latín. Sería como introducir desnudo artístico en la Facultad de Medicina sólo para inducir a los estudiantes a aceptar también el estudio algo más árido de la anatomía

Tampoco podemos preocuparnos, en esta época de organización, de la vocación de los estudiantes. A estudiar en esta Facultad viene quien quiere estudiar y, si después de un año o dos de estudio, el estudiante se da cuenta de que no es ésta su vocación, no es ninguna tragedia, pues no se le interrumpirá ninguna carrera profesional. Además sabemos que errores de vocación hay también en las facultades profesionales.

8. Se ha hablado también de la posibilidad de excluir ciertos estudios y otorgar becas para Europa. Esta no es una solución del problema y no corresponde a las finalidades de esta Facultad: la finalidad no es la de tener algunos especialistas preparados en Europa, sino la de tener aquí un centro vivo de estudios. Por esto yo no querría renunciar a las enseñanzas que incluí en el proyecto como eventuales y no obligatorias. Al contrario, yo aumentaría con el tiempo el número de estas enseñanzas, a considerarse algunas de ellas como verdaderas asignaturas (por ej. Historia del arte, Historia de la música -ya existentes en la Facultad) y otras como cursos libres o series de conferencias etc. Yo les confieso que, si yo fuera profesor de esta facultad, me gustaría constituir grupos de estudiantes para hacer con ellos cursos libres sobre materias no obligatorias, como Filología germánica o eslava, si hubiera interés para ellas. Esto porque yo considero que en este momento la tarea del profesor de esta facultad no es sólo la de enseñar las materias obligatorias y recompensadas, hacer el número de horas previstas en el plan de estudios y después no pensar más en la Facultad, sino, al contrario, la de dar a esta institución lo más que puede dar, con y sin sueldo, vivir una parte de su vida aquí, hacer aquí, en contacto continuo con los estudiantes, por lo menos una parte de su trabajo científico, entre estas paredes, no muy lindas, quizás, pero que encierran indudablemente un porvenir cultural, especialmente si los profesores sabrán trabajar con la abnegación que en este momento es justo y necesario pedirles. Les citaré en este sentido el ejemplo del ilustre profesor Hansen, que enseñó durante muchos años en Santiago, justamente durante la época de organización de aquella facultad de letras: el profesor Hansen enseñaba él sólo latín, griego, filología clásica y además, por algún tiempo, enseñó también, sin sueldo, lingüística española, justamente porque no había otro profesor que lo hiciera.

9. Finalmente, señores, espero que me perdonarán si me permito hacerles notar que hasta ahora hemos discutido casi sólo de la importancia de los estudios humanísticos y clásicos -de la que nadie duda, pues constituye la razón misma de la existencia de esta Facultad-, aunque sin subrayar lo suficiente que los estudios humanísticos no son sólo clásicos. Hemos discutido 
también de cosas un poco fútiles, como la importancia del latín y del griego -que todos admitimos- y de la dificultad de estos idiomas, que, desde un punto de vista lingüístico, es, según mi opinión, sólo un viejo prejuicio. Ahora yo creo que habría que hablar de lo concreto, volver al objetivo de estas reuniones, que es el plan de estudios para el 1951. Yo no pido que se discuta absolutamente mi plan: si les parece demasiado amplio para las actuales condiciones, lo que Vds. podrán ver mejor que yo, discutamos por lo menos el plan presentado por el prof. Cicalese, no muy distinto del mío, pero, quizás, más concreto, más adaptado a las posibilidades y necesidades inmediatas, más idóneo como base inmediata de discusión. Para lograr esto, yo renuncio formalmente a la discusión de mi proyecto y les ruego que discutamos el proyecto del profesor Cicalese, no para aprobarlo sin falta y sin objeción, sino justamente para tener una base de discusión concreta, para hablar de un plan real, modificable cuanto se quiera, y no de ideas generales sin relación directa e inmediata con lo concreto, con el objeto bien claro y definido de estas reuniones. 